\title{
浄水污泥からの凝集剤回収法とそのリン除去能の検討
}

\author{
市 原 真紀子*, ${ }^{*}$ 西 尾 孝 之*
}

\section{Alum Recovery from Water Clarifier Sludge as Coagulant and Phosphorus Removal by Recovered Alum}

\author{
Makiko ICHIHARA*, ${ }^{*}$ and Takayuki NISHIO* \\ * Osaka City Institute of Public Health and Environmental Sciences, 8-34 Tojo-cho, Tennoji-ku, Osaka 543-0026, Japan
}

\begin{abstract}
To recycle water clarifier sludge as a coagulant, we extracted alum from the sludge (hereafter called recovered alum (RA)) and attempted to obtain a high Al concentration and improve RA quality. RA was obtained by acidifying the sludge with concentrated sulfuric acid to adjust its $\mathrm{pH}$ below 2, and then centrifuging the mixture and decantating the supernatant. $\mathrm{RA}$ contained $\mathrm{Al}$ at $0.75-9.4 \%$ as $\mathrm{Al}_{2} \mathrm{O}_{3}$. To obtain a high $\mathrm{Al}$ concentration, it was better to use the sludge with a low water content. As impurity concentration increased with Al concentration, we purified RA by coagulating it with the addition of sodium hydroxide and resolubilizing it with the addition of dilute sulfuric acid. We were able to remove T-N, Fe, and $\mathrm{Mn}$ in the crude RA at $43.6 \%, 45.4 \%$ and $76.5 \%$ respectively by purification. When we used RA to model effluent containing $0.85 \mathrm{mg} \mathrm{P} \cdot \mathrm{L}^{-1}$ and underground water samples containing $1.14-1.52 \mathrm{mg} P \cdot \mathrm{L}^{-1}$, the phosphorus removal efficiency of RA was essentially comparable with that of commercial alum. RA removed over $90 \%$ phosphorus when the $\mathrm{PO}_{4}^{3-}$ : Al molar ratio was 1:5. As a conclusion, RA is a useful coagulant as long as we pay attention to the dose of contaminants.
\end{abstract}

Keywords: Water clarifier sludge; Coagulant; Recovered alum; Phosphorus removal efficiency; Reuse

\section{1.はじめに}

浄水場では凝集沈殿処理により浄水污泥が発生する。 その主成分は水道原水である河川水中に含まれる有機物 や粘土粒子であり，凝集剂由来のアルミニウムを微量に

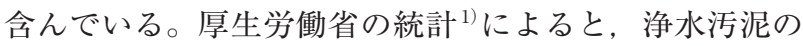
排出量は2008（平成 20）年度において年間約 28 万トン （乾燥重量）であり，浄水污泥中の污濁物質や有害物質 の含有量は低いものの, 浄水場排水に水質污濁防止法が 適用されることになってからは産業廃棄物として処理さ れている ${ }^{2)}$ 。そのため, 浄水污泥の有効利用については 様々な検討がなされており, 用途としてはセメント原料 などの建設資材 ${ }^{1,3)}$, 園芸用土 ${ }^{1,3)}$, リン除去資材 ${ }^{4 \sim 6)}$ な どが挙げられる。厚労省が 2004 年に策定した「水道ビ ジョン $\rfloor^{7)}$ の中では浄水污泥の有効利用率 $100 \%$ が施策目 標として揭げられているが，現状は約 $60 \%$ であり，処 分費用の削減や資源活用の観点からも更なる有効利用が 望まれている。

一方, 窒素・リンによる富栄養化は閉鎖性水域におけ る重要な問題であり, 湖沼における全窒素および全リン の環境基準の達成率は2009（平成 21）年度にようやく $50 \%$ を超えたところである ${ }^{8)}$ 。大阪市域においても富栄
養化の進行した公園池が存在し ${ }^{9}$, 周辺住民からは水質 改善が望まれている ${ }^{10)}$ 。さらに，近年ではリン資源の枯 渴問題 ${ }^{11)}$ が大きな関心を集めており，水環境におけるリ ン除去とその回収については積極的に取り組むべき課題 の一つである。

そこで, 我々は廃裹物である浄水污泥から凝集剂を回 収し, 環境水のリン除去について検討を行うこととした。 浄水污泥からの凝集剤の回収および再利用についてはこ れまでにも検討されており ${ }^{2,12 \sim 16)}$, 過去にはアメリカにお けるフルスケールでのテスト事例17)もあるが, 回収された 凝集剤のアルミニウム濃度の低さや, マンガンなど不純 物の高濃度含有といった問題が指摘されていた ${ }^{14,15,17,18)}$ 。 したがって本研究はこれらの問題点を踏まえ, アルミニ ウム濃度の高い凝集剤の回収や不純物の精製など, 改良 を加えた凝集剤の回収方法について検討した。回収され た凝集剤のリン除去能について性能試験を行い市販の凝 集剤と比較するとともに, 環境水への適用を行った。

\section{2. 実験材料および方法}

\section{1 実験に使用した浄水污泥とその組成分析}

浄水污泥は, 大阪市柴島浄水場の污泥濃縮槽から採取 したスラリー（S1）と, その脱水工程後である脱水ケーキ

* 大阪市立環境科学研究所 $\overline{\mathrm{T}}$ 543-0026 大阪市天王寺区東上町 8-34

ๆ連絡先 : mak-ichihara@city.osaka.lg.jp 
（D）を用いた。この浄水場では凝集剤として硫酸バンド を使用しており, 脱水方式は無薬注機械脱水である。また, S1 $3000 \mathrm{rpm}$ で 20 分間遠心分離後の残椬を S2 とし, 実 験には含水率の異なる上記 3 種類の浄水污泥を用いた。

浄水污泥中の全窒素（T-N), 全リン（T-P）, 重金属類, 強熱減量および含水率について測定した。

\section{2 浄水污泥からの凝集剂の回収とその成分分析}

浄水污泥からの凝集剤の回収方法を Fig. 1 に示す。浄 水污泥（S1, S2, D) に濃硫酸を加えて pH 2 以下として 約 1 時間覺拌し, $13,000 \mathrm{rpm}$ で 10 分間遠心分離後に上 澄みを分取し, 硫酸アルミニウムを含む溶液（以下，再 生バンドとする）を得た。再生バンドの作成には浄水污 泥 S1，S2，Dをそれぞれ乾重量で $8.4 \mathrm{~g}$ dry, $6.9 \mathrm{~g}$ dry, $40.8 \mathrm{~g}$ dry 使用し, 濃硫酸を乾重量当たり各 $0.30 \mathrm{~mL} \cdot \mathrm{g}^{-1}$ dry, $0.22 \mathrm{~mL} \cdot \mathrm{g}^{-1} \mathrm{dry}, 0.34 \mathrm{~mL} \cdot \mathrm{g}^{-1} \mathrm{dry}$ 添加した。なお, 污 泥 D は含水率が低く攪拌が困難であったため, 酸処理時 に蒸留水 $10 \mathrm{~mL}$ を追加して作成した。浄水污泥 S1, S2, $\mathrm{D}$ から得られた再生バンドの溶液量は, 乾重量当たり各 $17.9 \mathrm{~mL} \cdot \mathrm{g}^{-1} \mathrm{dry}, 4.9 \mathrm{~mL} \cdot \mathrm{g}^{-1} \mathrm{dry}, 0.9 \mathrm{~mL} \cdot \mathrm{g}^{-1} \mathrm{dry}$ であった。

再生バンドの T-N, T-P および重金属類濃度を測定し た。また, 浄水污泥の $\mathrm{Al}$ 含有量と再生バンドの $\mathrm{Al}$ 濃度 から, 再生バンド作成時の $\mathrm{Al}$ 回収率を算出した。

\section{3 再生バンドの精製とその成分分析}

$\mathrm{S} 1$ から作成した再生バンド (以下 S1 再生バンドとし, $\mathrm{S} 2$ および D も同様とする）を用い，不純物の除去を目 的とした精製を行った。その精製方法を Fig. 2 に示す。 再生バンドに水酸化ナトリウム溶液を加え所定の $\mathrm{pH}$ に 調整し, 再生バンド中の硫酸アルミニウムを水酸化アル ミニウムとして析出させた。この溶液を $3,000 \mathrm{rpm}$ で 10 分遠心分離後, 不純物を含む上澄みを除去し, 残椬を蒸 留水で溶解させた。これに硫酸を加えて pH 2 以下とし, 再生バンドを精製した（以下，精製バンドとする）。精 製条件は，精製時の $\mathrm{pH}$ を 4.5 または 6.0 に調整し，そ れぞれの $\mathrm{pH}$ において再生バンドの希釈率を 1 倍または 10 倍とした場合の 4 通りの条件（条件 A〜D）につい て検討を行った。希釈率が 1 倍の場合は S 1 再生バンド $50 \mathrm{~mL}, 10$ 倍の場合は同 $20 \mathrm{~mL}$ を蒸留水で $200 \mathrm{~mL}$ とし たものを用いて精製を行った。なお，D再生バンドは， $\mathrm{Al}$ や他の不純物が高濃度のためアルカリ凝集時に粘調 となり, $\mathrm{pH}$ 調整やその後の処理が困難であったため, S1 再生バンドを用いて精製を行った。

精製バンドの T-N, T-P および重金属類濃度を測定し, アルミニウム回収率および不純物の除去率を求めた。

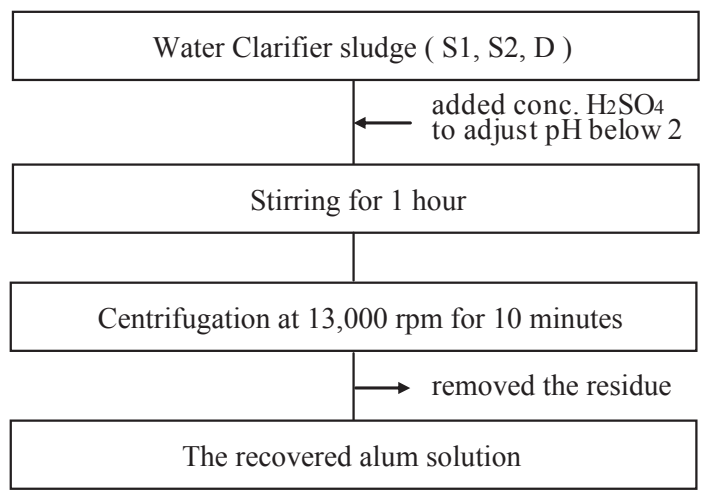

Fig. 1 Scheme of alum recovery process from water clarifier sludge.

\section{4 再生バンドおよび精製バンドによる凝集沈殿時 の負荷検討}

再生バンドおよび精製バンドを凝集剤として用いる際 には, 処理対象である環境水に対する污濁負荷の持ち越 しが懸念される。そこで, 再生バンドおよび精製バンド を凝集剤として用いた場合の処理水に与える污濁負荷に ついて検討した。凝集剤として, 再生バンド 3 種類, 精 製バンド 4 種類および市販の硫酸バンド（古河ケミカル ズ(株製の液体硫酸アルミニウム）の計 8 種類を用いた。 超純水（関東化学(株製）に $\mathrm{Al}$ 濃度が $20 \mathrm{mg} \cdot \mathrm{L}^{-1}$ となる よう各バンドを添加し, 水酸化ナトリウムを用いて $\mathrm{pH}$ を 7.0 に調整した。この超純水 $200 \mathrm{~mL}$ を $200 \mathrm{~mL}$ 容の ビーカーに取り，ジャーテスターを用いて $120 \mathrm{rpm}$ で 5 分間攪拌後 $50 \mathrm{rpm}$ で 10 分間攪拌し，約 1 時間静置した 後に上澄みを採水した。ガラス繊維ろ紙 (ADVANTEC 製 GS-25：孔径約 $1 \mu \mathrm{m}$ ）を用いてろ過したろ過水と未 ろ過水について T-N, $\mathrm{NO}_{2}^{-}-\mathrm{N}, \mathrm{NO}_{3}^{-}-\mathrm{N}, \mathrm{NH}_{4}^{+}-\mathrm{N}, \mathrm{T}-\mathrm{P}$, $\mathrm{PO}_{4}^{3-}-\mathrm{P}, \mathrm{Al}, \mathrm{Fe}, \mathrm{Mn}$ を測定した。

\section{5 再生バンドの性能試験}

性能試験用の試料水は, 水道水に硫酸アンモニウムお よびリン酸水素二ナトリウムを加え, $\mathrm{T}-\mathrm{N} 5.9 \mathrm{mg} \cdot \mathrm{L}^{-1}$ およ び T-P $0.85 \mathrm{mg} \cdot \mathrm{L}^{-1}$ としたモデル排水を用いた。モデル排 水は, 次項の環境試料として使用した地下水を模して各 濃度を設定した。また, 再生バンドの性能を検証するため, 市販の硫酸バンドを用い，合わせて性能試験を行った。

モデル排水を用いた実験では再生バンドおよび市販の 硫酸バンドの $\mathrm{Al}$ 濃度が $0.2 \sim 30 \mathrm{mg} \cdot \mathrm{L}^{-1}$ の範囲となるよ う, 段階的に各バンドを添加し, 塩酸および水酸化ナト リウムを用いて $\mathrm{pH}$ を 5.5〜 6.0 に調整した。このモデル 排水 $200 \mathrm{~mL}$ を $200 \mathrm{~mL}$ 容のビーカーに取り, ジャーテ スターを用いて $120 \mathrm{rpm}$ で 5 分間攪拌後 $50 \mathrm{rpm}$ で 10 分 間攪拌し，約 1 時間静置した後に上澄みを採水し, T-P を測定した。

\section{6 環境試料を用いた凝集沈殿試験}

環境試料における再生バンドのリン除去能を確認する ため, 大阪市内で 2010 年 12 月に採水した地下水 3 試料

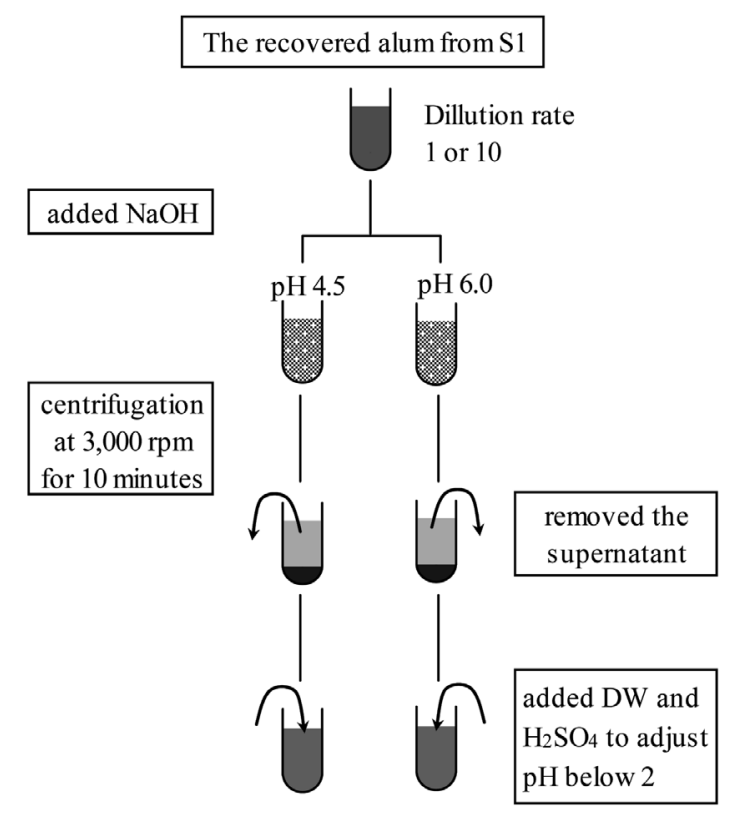

Fig. 2 Scheme of purification process from recovered alum. 
について，再生バンドおよび市販の硫酸バンドを用いた ジャーテストを行った。環境試料においては, まず硫 酸バンドの凝集最適 $\mathrm{pH}^{18)}$ とされる $\mathrm{pH} 5.5 \sim 8.0$ の範囲で ジャーテストを行い, 各試料の凝集最適 $\mathrm{pH}$ を求め, 設 定した $\mathrm{pH}$ に拉いてジャーテストを行った。各バンドの $\mathrm{Al}$ 添加量は $0.5 \sim 20 \mathrm{mg} \cdot \mathrm{L}^{-1}$ とし, $\mathrm{pH}$ 以外の条件は前述 の通りとした。

\section{7 分析方法}

浄水污泥中の各項目については底質調查方法 ${ }^{19)}$ に準拠 して測定した。再生バンド，精製バンドおよび試料水の $\mathrm{T}-\mathrm{N}, \mathrm{NO}_{2}^{-}-\mathrm{N}, \mathrm{NO}_{3}^{-}-\mathrm{N}, \mathrm{T}-\mathrm{P}, \mathrm{PO}_{4}^{3-}-\mathrm{P}$ の分析は $\mathrm{BL} \mathrm{Tec}$ 製 オートアナライザーIIIを用いて測定した。 $\mathrm{NH}_{4}{ }^{+} \mathrm{-N}$ は JIS K 0102 に準拠しインドフェノール青法により測定を行った。

重金属類は ICP 発光分析計（日本ジャーレルアッシュ 製 IRIS1000）および ICP 質量分析計（アジレント製 HP4500）により測定を行った。

\section{3. 結果および考察}

\section{1 浄水污泥の成分組成}

浄水污泥の成分組成測定結果を Table 1 に示す。含水 率は S1 が $95.8 \%, \mathrm{~S} 2$ が $86.2 \%$ ，D が $62.9 \%$ であた。 含水率以外の項目については 3 種類とも同程度の值を示 し, 重金属類では $\mathrm{Al}$ を $115.7 \sim 136.1 \mathrm{mg} \cdot \mathrm{g}^{-1} \mathrm{dry}$ 含有し, 次いで Fe $\left(24.9 \sim 30.2 \mathrm{mg} \cdot \mathrm{g}^{-1} \mathrm{dry}\right), \mathrm{Mg}\left(3.2 \sim 4.6 \mathrm{mg} \cdot \mathrm{g}^{-1}\right.$ dry), Mn (1.1〜 $\left.1.6 \mathrm{mg} \cdot \mathrm{g}^{-1} \mathrm{dry}\right)$ を多く含有していた。 有害金属である $\mathrm{Cr}$ や $\mathrm{Cd}, \mathrm{Pb}$ の含有量はいずれも $0.04 \mathrm{mg} \cdot \mathrm{g}^{-1} \mathrm{dry}$ 以下であった。 $\mathrm{S} 2$ と D は S1 を脱水濃縮 した污泥であり, 含水率が異なる以外はほぼ同じ組成で あることが確認された。

\section{2 再生バンドの成分組成}

再生バンドの成分組成測定結果を Table 2 に示す。再 生バンドの $\mathrm{Al}$ 濃度は $\mathrm{S} 1$ 再生バンドが $3,950 \mathrm{mg} \cdot \mathrm{L}^{-1}$, $\mathrm{S} 2$ 再生バンドが $13,300 \mathrm{mg} \cdot \mathrm{L}^{-1}, \mathrm{D}$ 再生バンドが 49,700 $\mathrm{mg} \cdot \mathrm{L}^{-1}$ であった。再生バンドの $\mathrm{Al}$ 濃度は $\mathrm{S} 1<\mathrm{S} 2<\mathrm{D}$ であり, 含水率の低い浄水污泥から, より $\mathrm{Al}$ 濃度の高 い再生バンドが得られた。再生バンド作成時には酸処理 により浄水污泥中の $\mathrm{Al}$ を硫酸アルミニウムとして溶解
させ，遠心分離し上澄みを回収しているが（Fig. 1)，こ のとき得られる溶液量は各浄水污泥に含まれる水分量に 依存する。すなわち, 各浄水污泥の $\mathrm{Al}$ 含有量 (乾量換算) は同程度であるが (Table 1), 含水率の低い浄水污泥の 方がより少ない溶液中に硫酸アルミニウムを回収するこ とになり, 高濃度の $\mathrm{Al}$ が得られたと考えられた。これは, 浄水污泥 (乾重量) 当たりに得られた再生バンドの溶液 量が D $<\mathrm{S} 2<\mathrm{S} 1$ であることからも明らかである。

市販の硫酸バンドの $\mathrm{Al}$ 濃度は JIS において定められ ており, 水道用は酸化アルミニウム $\left(\mathrm{Al}_{2} \mathrm{O}_{3}\right)$ として 8.0 $\sim 8.2 \mathrm{wt} \%^{20)}$, 一般用は同 $8.0 \%$ 以上 ${ }^{21)}$ である(いずれも 液体の場合)。今回作成した再生バンドを $\mathrm{Al}_{2} \mathrm{O}_{3}$ 濃度で 表すと S1，S2，Dの順に0.75，2.5，9.4\%であり，D再 生バンドがJIS 規格をほぼ満足していた。

一方, 再生バンド作成時の $\mathrm{Al}$ 回収率は 39〜 53\%で あった。ここで未回収の $\mathrm{Al}$ 量に着目すると, 作成に使 用した浄水污泥 (乾量換算) 当たりでは S1, S2, D の いずれも約 60〜 $70 \mathrm{mg} \cdot \mathrm{g}^{-1} \mathrm{dry}$ の $\mathrm{Al}$ が未回収であった。 浄水污泥中の $\mathrm{Al}$ は主に土壤粒子と凝集剂由来であると 考えられるが, 大阪市域における河川底質中の $\mathrm{Al}$ 含有 量は 26〜 $66 \mathrm{mg} \cdot \mathrm{g}^{-1} \mathrm{dry}{ }^{22}$ であり, 河川底泥を再生バンド 作成時と同様に酸処理したところ,その $\mathrm{Al}$ 回収率は $5 \%$ であった。これより, 硫酸処理では浄水污泥中の土壤由 来の $\mathrm{Al}$ はほとんど回収されないため, 回収率が約 5 割 以下に留まったと考えられた。

再生バンドは $\mathrm{Al}$ 以外に T-N, T-P, Fe, Mn を数十〜 数千 $\mathrm{mg} \cdot \mathrm{L}^{-1}$ 含有しており (Table 2), その濃度はいず れも $\mathrm{S} 1<\mathrm{S} 2<\mathrm{D}$ であった。 $\mathrm{A} 1$ と同時に不純物の高濃 度化が見られ, これらは再利用時に問題であるため, 再 生バンドの精製について検討した。

\section{3 再生バンドの精製結果}

S1 再生バンドを 4 通りの条件で精製した場合の各不 純物の除去率を Table 3 に示す。なお, 精製時には系全 体の物質収支を取り，各項目とも 82〜 109\%の範囲であ ることを確認している。

$\mathrm{A} 1$ の回収率は, 精製時の $\mathrm{pH}$ が 6.0 の場合はいずれも $90 \%$ 以上であったが, $\mathrm{pH} 4.5$ では条件 A（精製時の希釈

Table 1 Component of water clarifier sludge.

\begin{tabular}{cccccccccccccc}
\hline & WC & IL & T-N & T-P & Al & Fe & $\mathrm{Mn}$ & $\mathrm{Mg}$ & $\mathrm{Cu}$ & $\mathrm{Zn}$ & $\mathrm{Cr}$ & $\mathrm{Pb}$ & $\mathrm{Cd}$ \\
\hline S1 & 95.8 & 23.1 & 3.9 & 3.8 & 132.4 & 29.7 & 1.6 & 3.7 & 0.10 & 0.29 & 0.03 & 0.04 & $<0.01$ \\
S2 & 86.2 & 23.4 & 3.2 & 3.7 & 136.1 & 30.2 & 1.3 & 4.6 & 0.09 & 0.30 & 0.03 & 0.04 & $<0.01$ \\
$\mathrm{D}$ & 62.9 & 23.8 & 2.7 & 4.6 & 115.7 & 24.9 & 1.1 & 3.2 & 0.07 & 0.22 & 0.03 & 0.03 & $<0.01$ \\
\hline
\end{tabular}

WC: Water Content (\%)

IL: Ignition Loss (\%)

S1: Slurry from thickener after sedimentation tank

S2: Centrifuged S1 at 3000rpm for 20 minutes and removed supernatant solution

D: Dehydrated sludge from mechanical dehydration process

Table 2 Composition of recovered alum.

\begin{tabular}{lccrrrc}
\hline & T-N & T-P & Al & Fe & Mn & Al recovery (\%) \\
\hline RA from S1 & 78 & 119 & 3,950 & 457 & 67 & 53 \\
RA from S2 & 207 & 339 & 13,300 & 1,520 & 176 & 48 \\
RA from D & 456 & 1,240 & 49,700 & 6,850 & 587 & 39 \\
\hline CA & 2.3 & 4.0 & 68,300 & 7.7 & $<1$ & - \\
\hline
\end{tabular}


率が 1 倍）が $87.8 \%$ に対して条件 C（同 10 倍）は $45.6 \%$ であった。 pH 6.0 では，精製時に除去した上澄みの $\mathrm{Al}$ 濃度は数 $\mathrm{mg} \cdot \mathrm{L}^{-1}$ であり, ほとんど $\mathrm{Al}(\mathrm{OH})_{3}$ や $\mathrm{AlPO}_{4}$ と して沈殿したと考えられた。一方, $\mathrm{pH} 4.5$ では条件 $\mathrm{A}$, $\mathrm{C}$ においてそれぞれ $278 \mathrm{mg} \cdot \mathrm{L}^{-1}, 177 \mathrm{mg} \cdot \mathrm{L}^{-1}$ の $\mathrm{Al}$ が上 澄みに残存したため, 精製前の $\mathrm{Al}$ 濃度が $395 \mathrm{mg} \cdot \mathrm{L}^{-1}$ で ある条件 Cでは回収率が $50 \%$ 弱となった。丹保 ${ }^{23)} に よ$ ると, 硫酸アルミニウム溶液を水酸化ナトリウムで滴定 すると $\mathrm{pH}$ 4〜 5 において大きな緩衝能を有し，この間に おいては溶解性重合ポリマーである $\mathrm{Al}_{8}(\mathrm{OH})_{20}{ }^{4+}$ への水 和反応が生じるとされている。精製時は凝集に必要な緩 速攪拌や静置を行っていないため $\mathrm{Al}_{8}(\mathrm{OH})_{20}{ }^{4+}$ による凝 集が進みにくく，数百 $\mathrm{mg} \cdot \mathrm{L}^{-1}$ の $\mathrm{Al}$ が上澄みに残存した と考えられた。以上から, 高い $\mathrm{Al}$ 回収率を得るには $\mathrm{pH}$ 6.0 で精製するのが良いと考えられた。

$\mathrm{Fe}$ は $\mathrm{pH} 4.5$ ではいずれも $60 \%$ 以上の除去率であり, $\mathrm{pH}$ 6.0 では条件 B が $45.4 \%$, 条件 D は $14.3 \%$ であった。 $\mathrm{Fe}^{3+}$ は $\mathrm{Al}$ より水酸化物の溶解度積が小さいため, $\mathrm{pH} 4.5$ およ び $\mathrm{pH} 6.0$ ではそのほとんどが水酸化鉄として沈殿し, 除 去率は低くなるはずであるが, 予想と異なる結果であった。

Mn はいずれの場合も $76 \%$ 以上の除去率を示し, 特に 希釈率が 10 倍の場合 $90 \%$ 以上の高い除去率であった。 $\mathrm{Mn}$ は $\mathrm{Al}$ や $\mathrm{Fe}$ と比べて水酸化物生成の $\mathrm{pH}$ 領域がアル カリ側のため, 精製時はその多くが上澄みに存在し, 除 去されたと考えられた。関根 ${ }^{14)}$ は，精製時には Mnの析 出を少なくするために $\mathrm{pH} 4.5 \sim 6.5$ の酸性域の適值に止 めるのがよいと報告している。本結果からは, pH 4.5 と pH 6.0 の間に大きな除去率の差は見られなかった。

T-N は 43.6〜 61.6\% といずれも 50\%前後の除去率であ
り，T-P はいずれも除去率が $10 \%$ 以下と低かった。リン は精製時に $\mathrm{Al}$ と $\mathrm{AlPO}_{4}$ を生成するため除去不可能であ るが, 次項で述べるように再生バンド自身の T-P は凝集 剤として使用時に同時に沈殿除去されるため, 問題にな らないと考えられた。

以上から, $\mathrm{Al}$ 回収率と $\mathrm{Fe}$ 除去率を考慮すると条件 $\mathrm{B}$ (希釈率 1 倍, $\mathrm{pH}$ 6.0) が適当であると考えられ，この 場合 T-N $43.6 \%, \mathrm{Fe}$ を $45.4 \%, \mathrm{Mn}$ を $76.5 \%$ 除去する ことができた。

次に，本研究と既報における再生バンドの $\mathrm{Al}$ および 不純物の濃度を Table 4 に示す。本研究の Al 濃度は既 報と比べ高く，また精製バンドについては残椬の再溶 解時 (Fig. 2 の最終工程) に溶液量を減らすことによ り, $\mathrm{Al}$ 濃度を高めることが可能であった。精製バンド の Fe や Mn の濃度は Bishop ら ${ }^{17)}$ と比べ低く, 関根 ${ }^{14)}$ や Sengupta ${ }^{24)}$ と同程度であった。Petruzzelli ら ${ }^{25)}$ の Fe お よび Mn 濃度は本研究より 3〜4 桁低い值であったが, Petruzzelli らは精製時に市販のマクロポーラス型陽イオ ン交換樹脂を使用していた。元来廃棄物である浄水污泥 の有効利用という観点からすると, 特別な資材を用いな い方がより望ましいと考えられるため, pH 調整が主で ある本研究の精製方法は有用であると言えよう。以上か ら, 本研究で作成した再生バンドは既報における $\mathrm{Al}$ の 低濃度化, 鉄・マンガンの濃縮といった欠点を一定解消 したと考えられた。

\section{4 再生バンドおよび精製バンドによる凝集沈殿時 の負荷検討結果}

再生バンド，精製バンドおよび市販の硫酸バンドを用 いた凝集沈殿後の上澄み中の各濃度について Table 5 に

Table 3 Removal rate of impurities about purified RA.

\begin{tabular}{|c|c|c|c|c|c|c|c|}
\hline \multirow{2}{*}{$\begin{array}{l}\text { Purification of } \\
\text { RA from S1 }\end{array}$} & \multicolumn{2}{|c|}{ Purifying condition } & \multicolumn{4}{|c|}{ Removal rate } & \multirow{2}{*}{$\frac{\text { Recovery }}{\mathrm{Al}}$} \\
\hline & Dilution rate & $\mathrm{pH}$ & $\mathrm{T}-\mathrm{N}$ & T-P & $\mathrm{Fe}$ & $\mathrm{Mn}$ & \\
\hline Type A & 1 & 4.5 & 51.6 & 2.2 & 61.4 & 82.2 & 87.8 \\
\hline Type B & 1 & 6.0 & 43.6 & -8.2 & 45.4 & 76.5 & 93.4 \\
\hline Type C & 10 & 4.5 & 61.6 & 7.5 & 62.2 & 98.9 & 45.6 \\
\hline Type D & 10 & 6.0 & 52.4 & 1.7 & 14.3 & 94.0 & 94.4 \\
\hline
\end{tabular}

Table $4 \mathrm{Al}$ concentration and normalized concentrations of impurities in recovered alum of various studies.

\begin{tabular}{|c|c|c|c|c|c|c|c|}
\hline & $\mathrm{Al}$ & T-N & T-P & $\mathrm{Fe}$ & $\mathrm{Mn}$ & \multirow[t]{2}{*}{ Purification } & \multirow[t]{2}{*}{ Reference } \\
\hline & $\mathrm{mg} \cdot \mathrm{L}^{-1}$ & \multicolumn{4}{|c|}{$\mu \mathrm{g}$ Element / mg Al } & & \\
\hline $\mathrm{RA}$ from $\mathrm{S} 1$ & 3,950 & 20 & 30 & 116 & 17 & none & \\
\hline RA from $\mathrm{S} 2$ & 13,300 & 16 & 25 & 114 & 13 & none & Present \\
\hline RA from $D$ & 49,700 & 9 & 25 & 138 & 12 & none & study \\
\hline Purified RA from S1 (Type B) & 3,690 & 12 & 35 & 67 & 4 & a) & \\
\hline Ishikawa et al. & 5,800 & 10 & 25 & - & 17 & none & 12) \\
\hline Sekine & 21,200 & - & - & 145 & 0.3 & b) & 14) \\
\hline Bishop et al. & $1,970-2,700$ & - & - & 146 & 127 & none & 17) \\
\hline Sengupta et al. & $5,600 *$ & - & - & 47 & 3 & c) & 24) \\
\hline Petruzzelli et al. & $300-500 *$ & - & - & 0.002 & 0.001 & d) & 25) \\
\hline
\end{tabular}

* This value was before purification. Al concentration after purification was no available.

a) coagulation with alkaline and resolubilizing with thin sulfuric acid

b) coagulation with alkaline and resolubilizing with hydrochloric acid

c) composite membranes made of fine particles of chelating polymers entrapped in thin sheets of porous PTFE

d) ion exchange process using of commercial weak electrolyte carboxylate resin

RA: Recovered Alum 
示す。未ろ過水の結果では, T-N は硫酸バンドを用いた 場合 $0.01 \mathrm{mg} \cdot \mathrm{L}^{-1}$ であり, 再生バンドは $0.12 \sim 0.21 \mathrm{mg} \cdot \mathrm{L}^{-1}$, 精製バンドは $0.05 \sim 0.08 \mathrm{mg} \cdot \mathrm{L}^{-1}$ であった。いずれも $\mathrm{NO}_{2}^{-}-\mathrm{N}$ および $\mathrm{NO}_{3}-\mathrm{N}$ は検出されず，そのほとんどが $\mathrm{NH}_{4}{ }^{+}-\mathrm{N}$ であり，ろ過による除去は見られなかった。T-P については, 硫酸バンドは $0.01 \mathrm{mg} \cdot \mathrm{L}^{-1}$ 未満であり, 再 生バンドと精製バンドはともに $0.02 \sim 0.04 \mathrm{mg} \cdot \mathrm{L}^{-1}$ であっ たが，再生バンドおよび精製バンドにおいてもろ過後 の T-P は $0.01 \mathrm{mg} \cdot \mathrm{L}^{-1}$ 未満であった。再生バンドおよび 精製バンドの添加量から計算すると，単純に処理水中に 拡散した場合の T-P 濃度 $\left(0.5 \sim 1.2 \mathrm{mg} \cdot \mathrm{L}^{-1}\right)$ と比べ $1 〜 2$ 桁低い濃度で検出されており, リンについては再生バン ドおよび精製バンドからの負荷を自身で凝集沈殿したと 考えられた。

$\mathrm{A} 1$ は各バンドによる明確な濃度差は見られず，未ろ 過水では $0.26 \sim 0.54 \mathrm{mg} \cdot \mathrm{L}^{-1}$ の範囲であり, ろ過後はい ずれも $0.03 \mathrm{mg} \cdot \mathrm{L}^{-1}$ 以下となった。 $\mathrm{Fe}$ は，未ろ過水で は硫酸バンドが $0.01 \mathrm{mg} \cdot \mathrm{L}^{-1}$ 未満に対して再生バンドは $0.06 \sim 0.09 \mathrm{mg} \cdot \mathrm{L}^{-1}$, 精製バンドは $0.02 \sim 0.04 \mathrm{mg} \cdot \mathrm{L}^{-1}$ で あったが，いずれもろ過により $0.01 \mathrm{mg} \cdot \mathrm{L}^{-1}$ 以下となっ た。 $\mathrm{Al}$ や Fe では形成されたフロックがろ過操作により 除去されたと考えられたが，Mn はろ過による濃度低減 はほぼ見られず, 未ろ過水では硫酸バンドが $0.01 \mathrm{mg} \cdot \mathrm{L}^{-1}$ 未満に対して再生バンドは $0.20 \sim 0.29 \mathrm{mg} \cdot \mathrm{L}^{-1}$, 精製バン ドは $0.02 \sim 0.07 \mathrm{mg} \cdot \mathrm{L}^{-1}$ であった。

以上から, 再生バンドおよび精製バンドを凝集剤とし て用いた場合，各バンド中のリンは凝集沈殿時に同時に

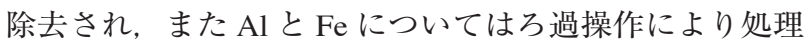
水から除去可能であった。 $\mathrm{NH}_{4}{ }^{+}-\mathrm{N}$ と $\mathrm{Mn}$ はろ過による除 去は困難であったが，いずれも再生バンドと比べ精製バ ンドでは処理水中の濃度の低減が見られた。このように,
処理水に与える環境負荷を考えると精製バンドの使用が 望ましいが，下廃水処理など処理目標水質の水準によっ ては再生バンドの利用も可能であると考えられた。再生 バンドおよび精製バンドはリサイクル品であるので, 実 際の使用時には精製処理にかかる労力と求められる処理 水質の両方を勘案し，処理対象に適したバンドを作成・ 使用することが現実的な使用法であると考えられた。

\section{5 再生バンドの性能試験結果}

再生バンドは市販の硫酸バンドと異なり，作成のたび に $\mathrm{Al}$ 濃度が変動することが考えられる。そのため,「再 生バンドまたは精製バンドの $\mathrm{Al}$ 濃度が異なっていても, $\mathrm{Al}$ 添加量当たりで比較するとリン除去能は同等である か」を検証する必要があると考えられた。そこで, 性能 試験においては $\mathrm{Al}$ 濃度の異なる 3 種類の再生バンド ( 1 再生バンド, S2 再生バンド, D 再生バンド）を用い, $\mathrm{A} 1$ 添加量当たりで比較した場合のそのリン除去能について 検証した。また，市販の硫酸バンドとの比較も行った。

ジャーテストの一例として S1 再生バンドを用いた結 果を Fig. 3 に示す。再生バンドの添加に伴いモデル排水 中の T-P 濃度は低下し, Al $5 \mathrm{mg} \cdot \mathrm{L}^{-1}$ 以上では $90 \%$ 以上 のリンが除去された。Fig. 4 に各再生バンドおよび硫酸 バンド添加量とリン除去能の関係を示す。各再生バンド は, それぞれの $\mathrm{Al}$ 濃度は異なるものの $\mathrm{Al}$ 添加量当たり で比較すると同等のリン除去能を示し, また市販の硫酸 バンドと同等のリン除去能を持つことが確認された。

\section{6 再生バンドの環境試料への適用}

大阪市内の地下水 3 試料 (UGW1〜3）について, 硫 酸バンドおよび再生バンドを用いたジャーテスト結果を

Fig. 5 に示す。なお, 前項で各再生バンドのリン除去能 が同等であることを確認したため, 今回は $\mathrm{Al}$ 濃度の最も 高い D 再生バンドを用いて実験を行った。ジャーテスト

Table 5 The pollution load in distilled water by coagulation with recovered alum, purified RA and commercial alum. Non filtrated supernatant solution

\begin{tabular}{|c|c|c|c|c|c|c|c|c|c|}
\hline & $\mathrm{T}-\mathrm{N}$ & $\mathrm{NO}_{2}^{-}-\mathrm{N}$ & $\mathrm{NO}_{3}^{-}-\mathrm{N}$ & $\mathrm{NH}_{4}^{+}-\mathrm{N}$ & T-P & $\mathrm{PO}_{4}{ }^{3-}-\mathrm{P}$ & $\mathrm{Al}$ & $\mathrm{Fe}$ & $\mathrm{Mn}$ \\
\hline RA from $\mathrm{S} 1$ & 0.21 & $<0.01$ & $<0.01$ & 0.17 & 0.04 & 0.01 & 0.48 & 0.07 & 0.29 \\
\hline RA from $\mathrm{S} 2$ & 0.13 & $<0.01$ & $<0.01$ & 0.10 & 0.02 & 0.01 & 0.52 & 0.09 & 0.22 \\
\hline RA from D & 0.12 & $<0.01$ & $<0.01$ & 0.09 & 0.02 & 0.01 & 0.34 & 0.06 & 0.20 \\
\hline \multirow[t]{4}{*}{ Purified RA from $\mathrm{S} 1$} & 0.05 & $<0.01$ & $<0.01$ & 0.04 & 0.02 & 0.02 & 0.48 & 0.04 & 0.06 \\
\hline & 0.08 & $<0.01$ & $<0.01$ & 0.05 & 0.04 & 0.02 & 0.31 & 0.02 & 0.07 \\
\hline & 0.06 & $<0.01$ & $<0.01$ & 0.03 & 0.03 & 0.02 & 0.40 & 0.04 & 0.02 \\
\hline & 0.05 & $<0.01$ & $<0.01$ & 0.02 & 0.02 & 0.01 & 0.26 & 0.03 & 0.02 \\
\hline $\mathrm{CA}$ & 0.01 & $<0.01$ & $<0.01$ & 0.01 & $<0.01$ & $<0.01$ & 0.54 & $<0.01$ & $<0.01$ \\
\hline \multicolumn{10}{|c|}{ Filtrated supernatant solution } \\
\hline & $\mathrm{T}-\mathrm{N}$ & $\mathrm{NO}_{2}^{-}-\mathrm{N}$ & $\mathrm{NO}_{3}^{-}-\mathrm{N}$ & $\mathrm{NH}_{4}^{+}-\mathrm{N}$ & T-P & $\mathrm{PO}_{4}^{3-}-\mathrm{P}$ & $\mathrm{Al}$ & $\mathrm{Fe}$ & $\mathrm{Mn}$ \\
\hline RA from $\mathrm{S} 1$ & 0.21 & $<0.01$ & $<0.01$ & 0.16 & $<0.01$ & $<0.01$ & 0.03 & $<0.01$ & 0.29 \\
\hline RA from $\mathrm{S} 2$ & 0.13 & $<0.01$ & $<0.01$ & 0.10 & $<0.01$ & $<0.01$ & 0.01 & 0.01 & 0.22 \\
\hline RA from $\mathrm{D}$ & 0.12 & $<0.01$ & $<0.01$ & 0.09 & $<0.01$ & $<0.01$ & 0.01 & $<0.01$ & 0.19 \\
\hline \multirow{4}{*}{ Purified RA from S1 } & 0.05 & $<0.01$ & $<0.01$ & 0.04 & $<0.01$ & $<0.01$ & 0.01 & $<0.01$ & 0.05 \\
\hline & 0.08 & $<0.01$ & $<0.01$ & 0.05 & $<0.01$ & $<0.01$ & 0.03 & 0.01 & 0.06 \\
\hline & 0.06 & $<0.01$ & $<0.01$ & 0.03 & $<0.01$ & $<0.01$ & 0.02 & $<0.01$ & 0.01 \\
\hline & 0.05 & $<0.01$ & $<0.01$ & 0.02 & $<0.01$ & $<0.01$ & $<0.01$ & 0.01 & 0.01 \\
\hline CA & 0.01 & $<0.01$ & $<0.01$ & 0.01 & $<0.01$ & $<0.01$ & $<0.01$ & $<0.01$ & $<0.01$ \\
\hline
\end{tabular}


に用いた地下水の性状を Table 6 に示す。地下水の T-P 濃 度は $1.14 \sim 1.52 \mathrm{mg} \cdot \mathrm{L}^{-1}$ であり, その 89〜 $100 \%$ が $\mathrm{PO}_{4}{ }^{3-}-\mathrm{P}$ であった。地下水により T-P 濃度が異なるため, Fig. 5 の横軸はリン酸当たりの $\mathrm{Al}$ 添加量（モル比）とし, 比較 としてモデル排水を硫酸バンド処理した結果も示した。

各地下水において, 再生バンドは硫酸バンドと同等の リン除去能を示した。なお, UGW2 は $\mathrm{Al}$ 添加量に伴う リン除去能が他の試料と比べて低い結果であったが，凝 集沈殿後の静置時間を長く（約 5 時間）した場合，他と 同程度までリン除去能が改善した。このように環境試料 の場合, 試料によってはフロックの沈降性が悪いものも あると考えられるが, 今回は未ろ過試料について分析し たため, ろ過操作を行うことにより改善されると考えら れた。

また, 地下水のリン除去能はモデル排水とほぼ同等で あり, $\mathrm{Al} / \mathrm{PO}_{4}{ }^{3-}$ (モル比) 当たりでは, 環境試料につい てもモデル排水とほぼ同等のリン除去能を示すことが確 認された。UGW1 は他の試料と比べて $\mathrm{Al} / \mathrm{PO}_{4}{ }^{3-}$ (モル比) 当たりのリン除去能が若干高かったが, UGW1 の SS 濃 度は他の試料と比べて高く（Table 6), 凝集沈殿の際に SS がフロック形成の核となり, リン除去能が向上した と考えられた。リン酸当たりの $\mathrm{Al}$ 添加量においては, $1: 5\left(\mathrm{PO}_{4}{ }^{3-}: \mathrm{Al}\right)$ のモル比で 9 割以上のリンが除去された。

なお, 凝集沈殿後の地下水の T-P 濃度は UGW2 を除 くと $0.07 \mathrm{mg} \cdot \mathrm{L}^{-1}$ 以下であった。富栄養化した環境水の

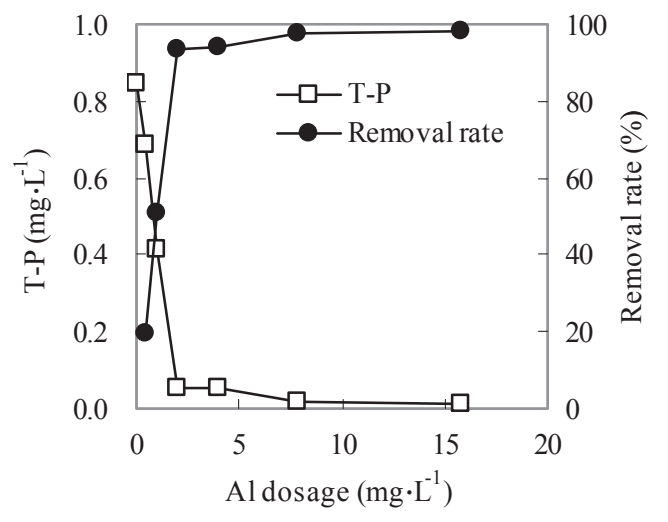

Fig. 3 Removal of phosphorus in the model effluent by coagulation with recovered alum from S1. Amount of added coagulant is expressed on $\mathrm{Al}$ basis.

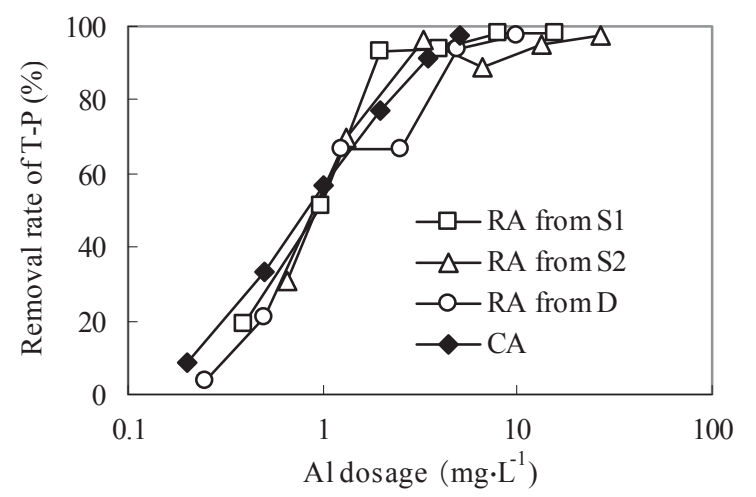

RA: Recovered Alum CA: Commercial Alum

Fig. 4 Removal rate of T-P in the model effluent by coagulation with recovered alum and commercial alum. Amount of added coagulant is expressed on $\mathrm{Al}$ basis.
直接浄化を目的とした場合, この值は必ずしも満足な值 とはいえないが, 下廃水処理などの発生源対策としては 十分なリン除去能を有すると考えられた。

\section{4. まとめ}

浄水污泥の有効利用として凝集剂（再生バンド）の回 収について検討した。従来より $\mathrm{Al}$ 濃度の高い再生バン ドの作成ならびに精製を試み, そのリン除去能を検証し, 以下の結果を得た。

1. 作成した再生バンドの $\mathrm{Al}_{2} \mathrm{O}_{3}$ 濃度は $0.75 \sim 9.4 \%$ で あり，その一部はJIS に定めるアルミニウム濃度を満 足していた。含水率の低い浄水污泥を用いると, よ りアルミニウム濃度の高い再生バンドを作成するこ とができたが，同時に不純物の高濃度化が見られた。

2. 再生バンドは不純物として窒素やリン, 鉄, マン ガンを高濃度含んでおり, 精製処理（アルカリ凝集 と酸処理による再溶解) により窒素, 鉄, マンガン はそれぞれ $43.6 \% ， 45.4 \% ， 76.5 \%$ 除去された。リ ンは除去不可能であったが, 凝集片として使用時に 沈殿除去されるため問題にならないと考えられた。

3. 再生バンドおよび精製バンドを凝集剤として用い た場合の処理水に与える負荷について検討した。Al と Feはろ過により処理水中の濃度は低減し, $\mathrm{Al}$ は $0.03 \mathrm{mg} \cdot \mathrm{L}^{-1}$ 以下, $\mathrm{Fe}$ は $0.01 \mathrm{mg} \cdot \mathrm{L}^{-1}$ 以下となった。 $\mathrm{NH}_{4}{ }^{+} \mathrm{-N}$ と $\mathrm{Mn}$ についてはろ過による除去は困難で あったが，いずれも再生バンドと比べ精製バンドで は処理水中の濃度の低減が見られた。

4. モデル排水（T-P $\left.0.85 \mathrm{mg} \cdot \mathrm{L}^{-1}\right)$ を用いたジャーテス トにおいて, 再生バンドはアルミニウム添加量当た りで比較すると市販の硫酸バンドと同等のリン除去

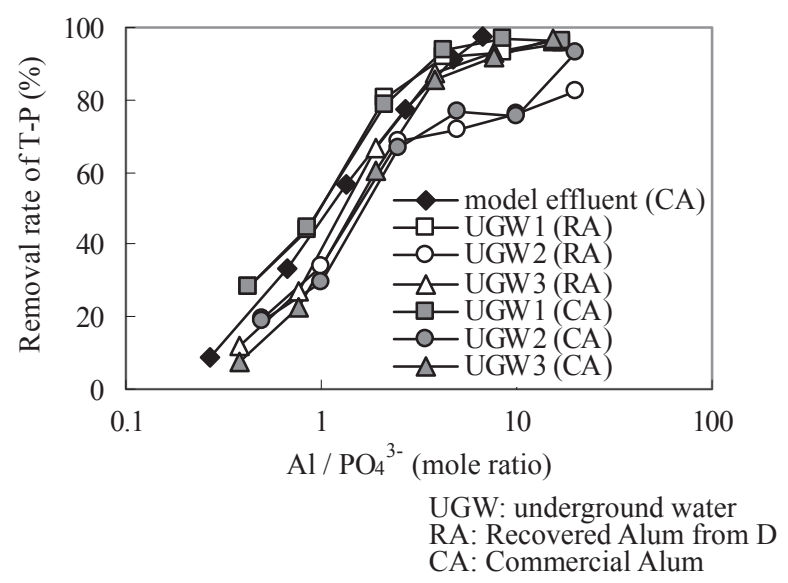

Fig. 5 Removal rate of T-P in the underground water by coagulation with recovered alum and commercial alum. Amount of added coagulant is expressed on mole ratio of $\mathrm{Al} / \mathrm{PO}_{4}{ }^{3-}$ basis.

Table 6 Water quality of underground water samples which were used in present study.

\begin{tabular}{lcccccc}
\hline & $\mathrm{pH}$ & WT & $\mathrm{SS}$ & $\mathrm{T}-\mathrm{N}$ & $\mathrm{T}-\mathrm{P}$ & $\mathrm{PO}_{4}{ }^{3-}-\mathrm{P}$ \\
\hline UGW1 & 7.49 & 17.7 & 21 & 10 & 1.52 & 1.36 \\
UGW2 & 7.56 & 12.9 & $<1$ & 1.7 & 1.14 & 1.14 \\
UGW3 & 6.93 & 19.6 & $<1$ & 4.7 & 1.51 & 1.50 \\
\hline UGW : underground water & & & $\mathrm{mg} \cdot \mathrm{L}^{-1}$ \\
WT : Water Temperature $\left({ }^{\circ} \mathrm{C}\right)$ & & &
\end{tabular}

水環境学会誌 Journal of Japan Society on Water Environment 
能を示した。

5. 地下水 3 試料（T-P $1.14 \sim 1.52 \mathrm{mg} \cdot \mathrm{L}^{-1}$ ) を用いた ジャーテストにおいても，再生バンドはアルミニウ ム添加量当たりで比較すると市販の硫酸バンドと同 等のリン除去能を示した。リン酸当たりのアルミ ニウム添加量では, $1: 5\left(\mathrm{PO}_{4}^{3-}: \mathrm{Al}\right)$ のモル比で 9 割以上のリンが除去された。

6. 本研究では, 再生バンドの $\mathrm{Al}$ の低濃度化, 鉄・ マンガンの濃縮といった既報における欠点を一定克 服し，また市販の硫酸バンドと同等のリン除去能が 確認された。処理水に与える環境負荷を考えると精 製バンドの使用が望ましいが，下廃水処理など処理 目標水質の水準によっては再生バンドの利用も可能 であると考えられた。使用時には精製処理にかかる 労力と求められる処理水質を勘案し, 処理対象に適 したバンドを選択することが望ましいと考えられた。

\section{謝 辞}

実験に使用した浄水污泥は大阪市水道局柴島浄水場か ら提供いただき，地下水の採水には大阪市環境局環境保 全部（現環境管理部）にご協力いただきました。また, 執筆にあたり, 大阪市立環境科学研究所の新矢将尚研究 主任には有益な助言をいただきました。ここに哚く感謝 の意を表します。

（原稿受付 2011 年 6 月 2 日) （原稿受理 2011 年 9 月 8 日）

\section{参 考 文 献}

1 ) 厚生労働省健康局水道課（2010）浄水污泥（浄水発生土）の 循環利用について, 環境省中央環境審議会循環型社会計画部会

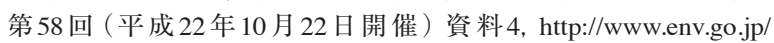
council/04recycle/y040-58/mat04.pdf (2011年4月時点).

2 ) 中野重和, 平嶋恒亮 (1988) 浄水污泥の廃水処理剂としての有 効利用に関する考察, 科学と工業, 62 (9), 345-352.

3 ) 厚生労働省 (2007) 水道ビジョンの主要施策と今後の課題, 厚 生労働省第 3 回水道ビジョンフォローアップ検討会 (平成 19 年 7月 31 日開催）参考資料, http://www.mhlw.go.jp/topics/bukyoku/ kenkou/suido/vision2/dl/one3-11_0001.pdf（2011年4月時点）。

4 ) 海野修司, 岡本正美, 永㴊正夫 (2003) 浄水污泥を用いたリン 除去技術, 土木学会論文集, 741/VII-28, 111-121.

5 ）玉置雅彦, 吉田重方 (2007) 浄水ケーキによる水中のリンおよび 硝酸態窒素の同時除去, 農業生産技術管理学会誌, 14 (2), 93-98.

6 ) 吉田重方 (2005) 浄水場から排出する水処理廃棄物の再資源化 〔2〕 - 浄水ケーキの水質浄化資材としての利用 - , 農業および園 芸, 80 (5), 582-588.
7 ) 厚生労働省健康局水道課 (2004) 水道ビジョン, http://www. mhlw.go.jp/topics/bukyoku/kenkou/suido/vision2/dl/vision.pdf (2011 年 4 月時点).

8 ）環境省水 - 大気環境局 (2010) 平成 21 年度公共用水域水質測定 結果, http://www.env.go.jp/water/suiiki/h21/full.pdf (2011 年4月時点).

9 ） 大島詔, 新矢将尚, 北野雅昭, 萩原拓幸, 後藤薰, 土永恒彌 (2008) 都市公園池の富栄養化特性とクロロフィル $\mathrm{a}$ との関係, 水環境学 会誌, 31 (11), 701-706.

10）大島詔, 西尾孝之, 高倉耕一, 山㟝一夫, 新矢将尚, 市原真紀子, 北野雅昭 (2010) 調査方法によるある親水性空間の利用形態及 び住民意識の違い, 第 13 回日本水環境学会シンポジウム講演集, 193-194.

11）原田洋平 (2011) リン資源の循環と再生利用に関する動向と展 望 (特集 迫り来るリン資源の枯渴に向けて), 水環境学会誌, 34 (A) (1), 2-6

12）石川精一, 上田直子, 奥村裕司, 飯田義和, 樋口雅之, 苗床江理, 徳永保範, 馬場健三 (2006) 上水污泥から回収した凝集剤の農薬 類等に対する凝集沈殿効果, 水環境学会誌, 29 (10), 653-658.

13）八木政雄, 原文俊, 松山明 (2007) 水道污泥による下水污泥中 でのりん固定に関する検討, 第44回下水道研究発表会講演集, 895-897.

14）関根勇二 (2001) 再生PACの生産と排水処理の改善 - システム 提案 -, 水道協会雑誌, 70 (9), 23-33.

15) David A. Cornwell and James A. Susan (1979) Characteristics of Acid-Treated Alum Sludges, J. Am. Water Works Assoc., 71 (10), 604608.

16) David A. Cornwell, Gary C. Cline, John M. Przybyla and David Tippin (1981) Demonstration testing of alum recovery by liquid ion exchange, J. Am. Water Works Assoc., 73 (6), 326-332.

17) Mark M. Bishop, A. T. Rolan, Tom L. Bailey and David A. Cornwell (1987) Testing of Alum Recovery for Solids Reduction and Reuse, $J$. Am. Water Works Assoc., 79 (6), 76-83.

18）藤田賢二 (2003)「水処理薬品ハンドブック」, pp.10, pp.125126 , 技報堂出版, 東京

19）日本環境測定分析協会 (1988)「改訂版 底質調查方法とその解 説」(環境庁水質保全局編), 175pp., 丸善, 東京.

20）日本規格協会 (2006) JIS K1450 水道用硫酸アルミニウム（水道 用硫酸ばんど), http://www.jisc.go.jp/app/pager?id=84155（2011年4 月時点)

21）日本規格協会（1970）JIS K1423硫酸アルミニウム（硫酸ばん ど), http://www.jisc.go.jp/app/pager?id=84182 (2011年4月時点).

22）大阪市環境局環境保全部 (2008) 平成19年度環境基準未達成 河川等調查報告書.

23）丹保憲仁 (1965) 水处理における凝集機構の基礎的研究 (III) 一硫酸アルミニウムによる粘土系濁質の凝集 - , 水道協会雑誌, 365, 25-37.

24) Arup K. Sengupta and Bo Shi (1992) Selective Alum Recovery from Clarifier Sludge, J. Am. Water Works Assoc., 84 (1), 96-103.

25) D. Petruzzelli, A. Volpe, N. Limoni and R. Passino (2000) Coagulants Removal and Recovery from Water Clarifier Sludge, Wat. Res., 34 (7), 2177-2182.

\section{[論 文 要 旨]}

$\mathrm{Al}$ の高濃度化や不純物の精製など, 改良を加えた浄水污泥からの凝集剤回収法について検討し, そのリ ン除去能を検証した。回収凝集剤（再生バンド）の $\mathrm{Al}_{2} \mathrm{O}_{3}$ 濃度は $0.75 \sim 9.4 \%$ あり，一部はJISに定める $\mathrm{Al}$ 濃度を満足していた。含水率の低い浄水污泥を用いると, より $\mathrm{Al}$ 濃度の高い再生バンドを作成可能であっ たが，同時に不純物の高濃度化が見られた。再生バンドは T-N や T-P, Fe, Mn を高濃度含んでいたが，精 製処理により T-P 以外は 43.6〜 76.5\% 除去され， $\mathrm{Al}$ の低濃度化や鉄・マンガンの濃縮といった既報におけ る欠点を一定克服した。モデル排水（T-P $0.85 \mathrm{mg} \cdot \mathrm{L}^{-1}$ ) や地下水（T-P $1.14 \sim 1.52 \mathrm{mg} \cdot \mathrm{L}^{-1}$ ）を用いたジャー テストにおいて，再生バンドは市販の硫酸バンドと同等のリン除去能を示し，1:5( $\left.\mathrm{PO}_{4}{ }^{3-}: \mathrm{Al}\right)$ のモル比 で 9 割以上のリンが除去された。

キーワード：浄水污泥；凝集剤；再生バンド；リン除去能；再利用 